\title{
New cephalosporins for the treatment of pneumonia in internal medicine wards
}

\author{
Tommaso Lupia ${ }^{1}$, Silvia Corcione ${ }^{1,2}$, Simone Mornese Pinna ${ }^{1}$, Francesco Giuseppe De Rosa $^{1}$ \\ ${ }^{1}$ Department of Medical Sciences, Infectious Diseases, University of Turin, Turin, Italy; ${ }^{2}$ School of Medicine, Tufts University, Boston, MA, USA \\ Contributions: (I) Conception and design: FG De Rosa, T Lupia; (II) Administrative support: None; (III) Provision of study materials or patients: \\ None; (IV) Collection and assembly of data: All authors; (V) Data analysis and interpretation: All authors; (VI) Manuscript writing: All authors; (VII) \\ Final approval of manuscript: All authors. \\ Correspondence to: Silvia Corcione, MD, PhD. Department of Medical Sciences, Infectious Diseases, University of Turin, Italy. \\ Email: corcione.silvia@gmail.com.
}

\begin{abstract}
The burden of hospital admission for pneumonia in internal medicine wards may not be underestimated; otherwise, cases of pneumonia are a frequent indication for antimicrobial prescriptions. Community- and hospital-acquired pneumonia are characterized by high healthcare costs, morbidity and non-negligible rates of fatality. The overcoming prevalence of resistant gram-negative and positive bacteria (e.g., methicillin-resistant Staphylococcus aureus, penicillin and ceftriaxone-resistant Streptococcus pneumoniae, extended-spectrum $\beta$-lactamases and carbapenemases producing Enterobacteriaceae) has made the most of the first-line agents ineffective for treating lower respiratory tract infections. A broad-spectrum of activity, favourable pulmonary penetration, harmlessness and avoiding in some cases a combination therapy, characterise new cephalosporins such as ceftolozane/tazobactam, ceftobiprole, ceftazidime/avibactam and ceftaroline. We aimed to summarise the role and place in therapy of new cephalosporins in communityand hospital-acquired pneumonia within the setting of internal medicine wards. The "universal pneumonia antibiotic strategy" is no longer acceptable for treating lung infections. Antimicrobial therapy should be individualized considering local antimicrobial resistance and epidemiology, the stage of the illness and potential host factors predisposing to a high risk for specific pathogens.
\end{abstract}

Keywords: Cephalosporins; nosocomial pneumonia (NP); community-acquired pneumonia (CAP); methicillinresistant Staphylococcus aureus (MRSA); influenza; multi-drug resistant bacteria

Submitted Jan 09, 2020. Accepted for publication May 29, 2020.

doi: $10.21037 /$ jtd-20-417

View this article at: http://dx.doi.org/10.21037/jtd-20-417

\section{Introduction}

Pneumonia is one of the most common indications for the antibiotic prescription (19.2\%), followed by skin and soft tissue infections (SSTIs; 9.0\%) and intra-abdominal infections (IAIs; $7.0 \%$ ) (1). Despite advances in clinical treatment and antibiotic therapy, pneumonia is still associated with high morbidity and mortality worldwide (2-4). The burden of hospital admissions for pneumonia is high (5-7): twenty-four to $75 \%$ of these patients are expected to be admitted in internal medicine wards (IMWs) (8-12). Community-acquired pneumonia (CAP) is associated with significant costs, high rate of hospitalization $(3,4)$ and intensive care unit (ICU) admissions (2,5). Mortality rate is increased up to $40 \%$ by several factors, as older age or comorbidities (13). Nosocomial pneumonia (NP) accounts for approximately $25 \%$ of the total infections harbored in the ICU and such circumstances have an enormous effect on the length of hospital stay and hospital related cost, with a mortality of between $27 \%$ to $50 \%$ (14). The efficacy of the treatment is even more compromised in countries where antibiotic persists, and this allows nosocomial infections with limited options for adequate antimicrobial treatment (15). "Old" cephalosporins (e.g., ceftriaxone, 
cefepime, ceftazidime) are commonly used agents in the treatment of different bacterial infections, including lower respiratory tract infections (LRTIs), thanks to their broadspectrum activity, well-characterized pharmacological properties and low rate of adverse events (16). The overcoming prevalence of extended-spectrum $\beta$-lactamases (ESBLs), carbapenemases producing Enterobacteriaceae (CPE), chromosomal AmpC $\beta$-lactamases makes these drugs ineffective to treat these infections. Furthermore, the emergence of multi-drug resistant (MDR) Grampositive bacteria such as methicillin-resistant Staphylococcus aureus (MRSA), methicillin-resistant coagulase-negative Stapbylococci (MR-CoNS), penicillin- and ceftriaxoneresistant $S$. pneumoniae (PRP and CRP respectively) and resistant Enterococci makes the management and treatment of these isolates challenging $(17,18)$. Pushed by the need of new antimicrobial agents, cephalosporins had been through significant changes with the introduction of new generation agents such as ceftobiprole $(19,20)$ and ceftaroline $(21,22)$, ceftolozane/tazobactam (C/T) (23) or ceftazidime/ avibactam (C/A) (24). Several studies have highlighted the non-inferiority of the new cephalosporins regarding their comparators (19-23,25,26). Fundamental strengths of these contemporary cephalosporins include an attractive spectrum of activity against MDR bacteria combined with high pulmonary penetration, proven harmlessness, and in some case, avoid combined therapy (15). We aimed to review the role and place in therapy of new cephalosporins in CAP and hospital-acquired pneumonia (HAP) in the setting of IMWs.

\section{Epidemiology of pneumonia in internal medicine}

The burden of Gram-positive in pneumonia is central (27), and Streptococcus pneumoniae is the most common bacteria causing CAP. Furthermore, approximately $16 \%$ of nosocomial types of pneumonia are a consequence of $S$. aureus infection (24). There is a close connection between influenza A virus disease and the subsequent or concurrent $S$. aureus infection: influenza A virus may increase the adhesion of $S$. aureus to respiratory tract cells boosts its proteases and simultaneously enhancing viral replication (28). For the above reasons, nasal carriers of $S$. aureus, which include from $20 \%$ to $83.7 \%$ of the general population, are at high-risk for secondary staphylococcal-pneumonia following influenza A (28).

Pneumonia due to Gram-negative bacteria (GNB), notably Enterobacteriaceae and Pseudomonas aeruginosa (PA), constitutes approximately $2 \%$ of cases of CAP, despite the increment in special populations such as older adults and high comorbid subjects $(29,30)$. Furthermore, resistant strains are rising; notably, PA and MRSA that were reported in about $6 \%$ of CAP $(31,32)$. As a matter of fact, according to current suggested treatments for CAP, MRSA and PA are two of the major disease-causing that would not be covered adequately with the existing strategies (29-32). Regarding HAP Enterobacteriaceae (e.g., Klebsiella spp., Enterobacter spp., and Serratia spp.), PA, and Acinetobacter baumannii, need to be considered (33-35). ESBL-producing Enterobacteriaceae and CPE related pneumonia remain a rare event in IMWs, especially in patients without prior known colonization (36-38). To systematically treat pneumonia, should be individualized the therapy considering local antimicrobial resistance and epidemiology, the stage of the illness and potential host factors predisposing to a high risk for specific pathogens (33-35).

\section{Overview on new cephalosporins in the treatment of pneumonia in IMWs}

\section{Ceftolozane-tazobactam}

This new cephalosporin combines in itself an innovative anti-pseudomonal cephalosporin, ceftolozane, albeit with pronounced similarity to ceftazidime structure, and the renowned $\beta$-lactamase inhibitor tazobactam (26). $\mathrm{C} / \mathrm{T}$, already approved for complicated urinary tract infections(cUTI) (38) and complicated intra-abdominal infection (cIAI) (39) at a dose of $1.5 \mathrm{~g}$ (i.e., with the ratio of 1:0.5, respectively ceftolozane and tazobactam, every $8 \mathrm{~h}$ ) has recently been approved, to twice the previous reported daily dose, in the phase III study ASPECT-NP (23), for treatment of NP, by the U.S. Food and Drug Administration (FDA) (40) and European Medicines Agency (EMA) (41).

\section{Antimicrobial properties of $\mathrm{C} / \mathrm{T}$}

$\mathrm{C} / \mathrm{T}$ is active in vitro against many important GNB, including multidrug- (MDR) or extensively drug- (XDR) resistant Pseudomonas spp. and ESBLs Enterobacteriaceae $(42,43)$. As evidence of it, Farrell et al. have reported that $\mathrm{C} / \mathrm{T}$ is the most active agent against PA (44) confirmed in several studies against strains grown in biofilms $(45,46)$.

Ceftolozane showed an elevated activity toward the essential penicillin binding proteins (PBPs; e.g., PBP1b, PBP1c, PBP2 and PBP3) of PA (47-50) and more stability against the chromosomal AmpC $\beta$-lactamase of $\mathrm{PA}$ and less 
reliance from its efflux pumps (e.g., Mex) or entry porins (e.g., OprD) (51,52) compared to ceftazidime.

Data from the surveillance network by Zilberberg et al. have shown that $22 \%$ of $\mathrm{PA}$ isolates from pneumonia are MDR (53) similar to those reported by Sader et al. (54) from the INFORM study. Moreover, INFORM study showed a rates of XDR PA among low respiratory isolates from $9.0 \%$ to $11.2 \%$ (54). In a multicenter evaluation $\mathrm{C} / \mathrm{T}$ has retained its sensitivity (55) against the $36 \%$ of meropenem nonsusceptible PA strains examined. Furthermore, according to Humphries et al. among isolates resistant to all traditional antipseudomonal beta-lactams, $52.4 \%$ were susceptible to $\mathrm{C} / \mathrm{T}$ and whereas $36.4 \%$ of $\mathrm{C} / \mathrm{A}$-resistant isolates were susceptible to $\mathrm{C} / \mathrm{T}$ (56). Pogue and colleagues (57) have recently compared $\mathrm{C} / \mathrm{T}$ to polymyxin or aminoglycosidesbased regimens supporting the preferential use of $\mathrm{C} / \mathrm{T}$ to treat NP due to the more favourable clinical cure, renal profile and comparable mortality rate (57-61).

\section{Clinical trials for $\mathrm{C} / \mathrm{T}$ in pneumonia}

In the ASPECT-NP trial (23), a randomized, controlled, double-blind, phase III non-inferiority trial, C/T (2 g ceftolozane and $1 \mathrm{~g}$ tazobactam every $8 \mathrm{~h}$ ) was compared to meropenem ( $1 \mathrm{~g}$ every $8 \mathrm{~h}$ ) to assess efficacy and safety in treating GNB-related NP with antimicrobial regimens lasting eight to 14 days. Clinicians from 263 hospitals in 34 countries have enrolled 726 patients, over 18 years old, subject to mechanical ventilation (MV) and randomized (1:1) to the C/T or meropenem group: the main focus of treatment was ventilator-associated pneumonia (VAP) which counted the $71 \%(\mathrm{~N}=519)$ of infections and 207 subjects (29\%) had a diagnosis of HAP or ventilated-HAP (23). The first goal was to evaluate all-cause mortality at day 28 in the intention to treat population (ITT): $\mathrm{C} / \mathrm{T}$ was noninferior to meropenem in terms of both 28-day all-cause mortality [ $\mathrm{N}=87$ (24\%) and $\mathrm{N}=82(25.3 \%)$ respectively; weighted treatment difference $1.1 \%$ ( $95 \%$ CI: $-5.1 \%$ to $7.4 \%)]$. These findings were confirmed in clinical cure at test-of-cure (TOC) $[\mathrm{N}=197$ (54\%) and $\mathrm{N}=194$ (53\%) in the $\mathrm{C} / \mathrm{T}$ and meropenem groups, respectively; weighted treatment difference $1.1 \%$ (95\% CI: $-6.2 \%$ to $8.3 \%)$ ] (23). Thus, outcomes have supported the role of $\mathrm{C} / \mathrm{T}$ as an alternative to carbapenems-based regimens. There was a trend toward higher rates of adverse events in the $\mathrm{C} / \mathrm{T}$ compared to meropenem group ( $42 \%$ vs. $36 \%$ ) but the study did not have enough statistical power to detect clearly this difference (23). Further phase IV studies aimed at assess the risk-benefit profile of $\mathrm{C} / \mathrm{T}$ with careful observation and surveillance in the clinical practice are needed (62).

\section{Lung penetration of $\mathrm{C} / \mathrm{T}$}

Lung penetration of $\mathrm{C} / \mathrm{T}$ has been evaluated in two phases I trials. A standard dose of C/T (e.g., $1.5 \mathrm{~g}$ every $8 \mathrm{~h}$ ) has proved to be successful in reaching pharmacokinetic (PK)/ pharmacodynamic (PD) target in epithelial lining fluid (ELF) in healthy individuals, for pathogens with minimum inhibitory concentration (MIC) within current susceptibility breakpoint of up to four milligrams per litre $(63,64)$. In the ASPECT-NP trial (23), the $3 \mathrm{~g}$ dose was tailored for achieving maximum antibacterial activity in the lungs, even against GNB showing a MIC higher than of $8 \mu \mathrm{g} / \mathrm{L}(62,65)$. In healthy individuals, pulmonary the dose of $3 \mathrm{~g}$ every $8 \mathrm{~h}$ can reach ELF concentrations of $>8 \mathrm{mg} / \mathrm{L}$ for $40 \%$ of the treating period and $4 \mathrm{mg} / \mathrm{L}$ for $50 \%$ of the treating period in the nearly overall of patients $(62,65)$. Ceftolozane seemed to practically clear $(92 \%)$ as an unaffected component by the renal route (40-42). Despite the reduction of dosages in patients with impaired renal function, $\mathrm{C} / \mathrm{T}$ schedule for pneumonia remains loyal to time-driven $\mathrm{PK}$, maintaining time between doses unchanged (q8 hours) $(23,62)$.

\section{Place in therapy of $\mathrm{C} / \mathrm{T}$ within IMW}

Different researches have studied risk factor for rectal colonization by ESBL such as advanced age, multiple medical conditions (e.g., recurrent UTIs, obstructive UTIs, diabetes mellitus, Charlson index score $>3$ ), prior past hospitalizations, recent antibiotic therapy (particularly third-generation cephalosporins and fluoroquinolones) and trips to highly endemic countries (e.g., Eastern Mediterranean countries, South-East Asia) (66-68). The overuse of carbapenems due to their efficacy against ESBL isolates resulted has helped to increased drug resistance. $\mathrm{C} / \mathrm{T}$ has been proposed as part of carbapenem-sparing strategies (Table 1) (70). Moreover, it is known that PA is a not uncommon cause of severe pneumonia, especially in patients with chronic obstructive pulmonary diseases (COPD), bronchiectasis or former smokers, with a high mortality rate (29-32,71). C/T may be an actual and future option as "backbone" of the anti-pseudomonal regimens, flanked by a second agent, such as aminoglycoside, fosfomycin, colistin or according to the local epidemiology, a fluoroquinolone $(70,72)$.

\section{Ceftobiprole}

Ceftobiprole medocaril, a fifth-generation, extended- 
Table 1 Possible place in therapy of new cephalosporins within guidelines for the management of pneumonia

Gram-positive antibiotics with MRSA activity
Glycopeptides
Vancomycin
Oxazolidinones
Linezolid
New cephalosporins
Ceftobiprole
Ceftaroline

Gram-negative antibiotics with antipseudomonal activity: $\beta$-lactam-based agents

Antipseudomonal penicillins

Piperacillin/tazobactam

Cephalosporins

Cefepime

Ceftazidime

New cephalosporins

Ceftolozane/tazobactam

Ceftazidime/avibactam

Carbapenems

Meropenem

Imipenem

Monobactams

Aztreonam

Gram-negative antibiotics with antipseudomonal activity: non- $\beta$-lactam-based agents

\section{Fluroquinolones \\ Ciprofloxacin \\ Levofloxacin}

Aminoglycosides

Amikacin

Gentamicin

Tobramycin

Polymyxins

Colistin

Polymyxin B

Adapted from Kalil et al. (69). MRSA, methicillin-resistant Staphylococcus aureus. spectrum cephalosporin, was currently endorsed in key European countries for the management of adult CAP (19), non-ventilator associated HAP (20) and for SSTIs, including diabetic foot (73).

\section{Antimicrobial properties of ceftobiprole}

Cell wall synthesis can be inhibited by ceftobiprole, due to its tight bindings to some PBPs of Gram-positive and Gram-negative pathogens (74). Furthermore, ceftobiprole can also interfere with $\beta$-lactams-resistant or poorly susceptible PBPs, including PBP2A of MRSA and MR-CoNS or PBP2x typical in PRP and CRP strains (74-76).

Concerning $\beta$-lactamases, ceftobiprole was recalcitrant to lytic activity by the PC1 staphylococcal penicillinase, to the class A (TEM-1 $\beta$-lactamase, SHV and K1 $\beta$-lactamase of Klebsiella oxytoca), and the chromosomal AmpC-type $\beta$-lactamases of Enterobacteriales and PA, but labile to hydrolysis by class $\mathrm{B}$, class $\mathrm{D}$ enzymes and by class A ESBLs $(77,78)$.

Ceftobiprole displays high efficacy against several Grampositive pathogens including methicillin-susceptible $S$. aureus (MSSA) and MRSA also for strains with a reduced susceptibility to linezolid, daptomycin or vancomycin and against Gram-negative pathogens, including PA and notESBL-producing Enterobacteriaceae $(74,79,80)$.

Results from a 5 -year antibiotic surveillance program in Europe on ceftobiprole (SENTRY, 2005-2010), have demonstrated high effectiveness against some of the leading cause of CAP, with $99.3 \%(\mathrm{~N}=4,443)$ S. pneumoniae isolates testing susceptible and promising results in both Haemophilus influenzae and Moraxella catarrbalis (81).

In the surveillance study TRUST, ceftobiprole was defined as one of the most effective cephalosporins investigated and systematically accredited in clinical review literature against $S$. pneumoniae with MIC50 and MIC90 two-fold lower than ceftriaxone (82).

Nevertheless, it is a potent bactericidal agent against MRSA that sets ceftobiprole at a distance from other cephalosporins (83-88). In the time-kill analysis, ceftobiprole was bactericidal against community-induced as well as nosocomial MRSA strains (83-88).

In the SENTRY study (81), $26.9 \%$ of $S$. aureus clinical isolates were MRSA, and $98.3 \%$ of these strains were susceptible to ceftobiprole, also in strains resistant in vitro to linezolid, vancomycin, and daptomycin: efficacy on linezolid-resistant MRSA was also confirmed by the CLASS study, assessing the in vitro action of ceftobiprole, issued by 
Rossolini et al. across 19 countries (86).

Furthermore, ceftobiprole, disclosed action against PA (64.6\% disposed of by the EUCAST-specific susceptibility breakpoint of $4 \mu \mathrm{g} / \mathrm{mL}$ ) that was less than cefepime $(78.6 \%$ susceptible) and ceftazidime (75.4\% susceptible) $(81,89-91)$.

\section{Clinical trials for ceftobiprole in pneumonia}

Two phase III trials demonstrated the efficacy and safety of ceftobiprole (19-20). The first one was a non-inferiority, double-blinded, multicentre, randomised study in 638 patients hospitalised for the treatment of severe CAP (19). The authors, compared ceftobiprole medocaril $(500 \mathrm{mg} / 8 \mathrm{~h})$ with ceftriaxone $(2 \mathrm{~g} /$ day) with optional linezolid (600 mg/12 h)-when MRSA or ceftriaxone-resistant S. pneumoniae was thought to be involved (19).

Ceftobiprole was found not inferior to ceftriaxone, whether as monotherapy or combined with linezolid (19).

Awad and colleagues (20) in a double-blinded, multicentre randomized study comparing ceftobiprole medocaril to ceftazidime and linezolid in 781 patients treated for HAP and VAP showing non-inferiority against comparators, with the exception of patients with VAP (20).

Possible explanations for these results are the insufficient sample size, a substantial conglomeration of baseline clinical features and appreciable heterogeneity in the VAP subgroup. Besides, another critical statistical difference was perceived in the subgroup of subjects with microbiological evidence of MRSA infection $(94.7 \%$ in the ceftobiprole group vs. $52.6 \%$ in the ceftazidime plus linezolid group [difference, 42.1 (95\% CI: 17.5-66.7)]. For the secondary effectiveness criteria, the microbiological eradication rates at the end of management visit in patients with HAP were comparable in the ceftobiprole and ceftazidime/linezolid groups (20). Interestingly, in patients with HAP requiring MV for less than $48 \mathrm{~h}$, clinical outcomes were in favour of ceftobiprole $(20,92,93)$.

\section{Lung penetration of ceftobiprole}

ELF concentrations of ceftobiprole were assessed in fit subjects at steady-state: mean ceftobiprole concentrations in the ELF were lower than in the plasma $(94,95)$. Population PK demonstrating grounded on these data showed that average dissemination into the ELF was 25.5\% (interquartile range, 7.9-30.4\%) (95-97). In the murine model of pneumonia (95), lung penetration of ceftobiprole, based on AUC values in the ELF and plasma, was more elevated (median 68.8\%) than in healthy individuals. However, the calculated ELF levels of antibiotics may barely predict $\beta$-lactam concentrations at the site of infection (96), specifically in studies in healthy volunteers. A review of clinical studies examining the ELF concentrations of ceftobiprole with those of other cephalosporins displays that lung penetration with the bulk agents was similar to that observed with ceftobiprole $(94,97)$.

\section{Place in therapy of ceftobiprole within IMW}

Ceftobiprole may be a good option in severe CAP leading to complications associated with influenza, in which practical coverage of community-associated MRSA (CAMRSA) should be guaranteed (Figure 1) (92) especially in patients with diabetes, obese, COPD or patients with lung abnormalities, patients older than 65 years or patients with underlying malignancies $(92,93,98)$. Scheeren et al. (98), in a post-hoc analysis from the two phase III trials (19-20), evaluated the consequences in a smaller group of high risk subjects with community induced or NP and they showed advantages of ceftobiprole compared to other medications in terms of premature progress in the recovery for highrisk patients, and in high-risk HAP and patients with up to ten underlying comorbidities at baseline (98). Thanks to its safety and efficacy also in frail population, ceftobiprole should be considered in severe pneumonia and in patients at high risk of mortality $(92-94,98,99)$. Ceftobiprole might be useful also in post-obstructive pneumonia, a clinical entity due to an infection of the lung parenchyma distal to the bronchial obstruction in lung cancer patients, notably to endobronchial or extraluminal obstruction due to cancer growth (100). Post-obstructive pneumonia presented a polymicrobial flora predominantly with the high rate of gram-positive pathogens, including MRSA: ceftobiprole monotherapy due to its safety may guarantee a low risk of an adverse event in this frail population (100).

Guidelines for NP $(69,101)$ demand rapid empiric antimicrobial regimens using a combination of antibiotics grounded in local patterns and patient risk factors. Furthermore, initial empirical monotherapy might be used whenever possible to decrease the risk of MDR growth $(70,102)$. Ceftobiprole combines an excellent spectrum for pathogens involved in HAP, with low risk and low rate of MDR GNB, in frail patients admitted to the hospital at high risk of adverse events caused by non- $\beta$-lactam anti-MRSA-agents as well as MRSA infection. Alongside qualities above mentioned, ceftobiprole reports a minimal risk in the selection of resistant mutants in Gram-positive or GNB and no significant impact on the healthy human intestinal flora (92-94). 


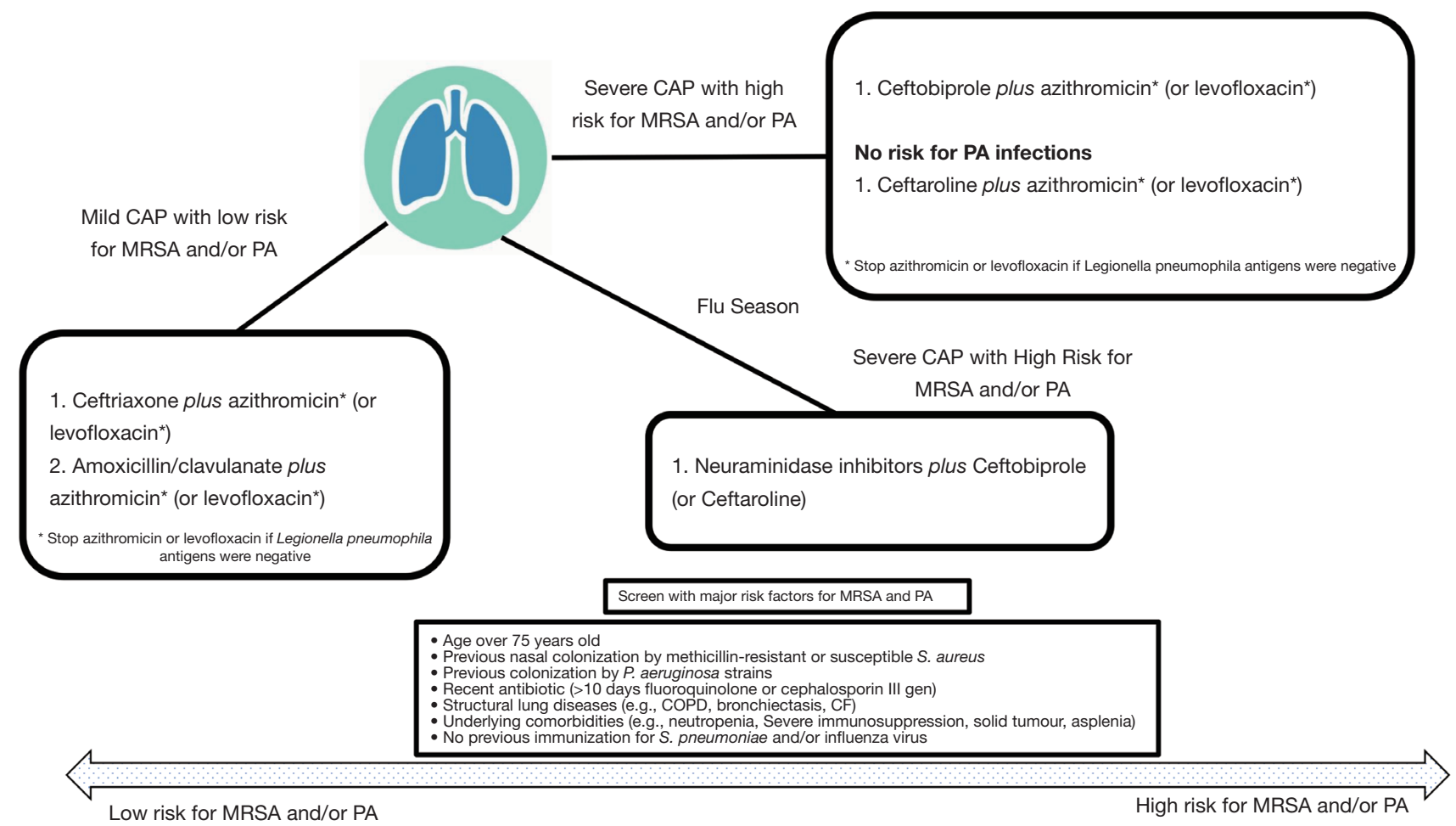

Figure 1 Place in therapy of ceftobiprole and ceftaroline in community-acquired pneumonia. CAP, community-acquired pneumonia; MRSA, methicillin-resistant Staphylococcus aureus; PA, Pseudomonas aeruginosa; COPD, chronic obstructive pulmonary disease; CF, cystic fibrosis.

\section{$C / A$}

$\mathrm{C} / \mathrm{A}$ is an intravenously third-generation cephalosporin (i.e., ceftazidime) with the non- $\beta$-lactam $\beta$-lactamase inhibitor avibactam (103). C/A was previously validated for cIAI (104) and cUTI (105) therapy and has demonstrated activity against common GNB even with the expression of clinically relevant class A, C and some D Ambler's $\beta$-lactamases or Enterobacteriaceae-producing chromosomal AmpC, ESBLs, and OXA-48 enzymes (103).

\section{Antimicrobial properties of C/A}

Ceftazidime is primarily an inhibitor of $\mathrm{PBP} 3$ : adhering to PBPs, thereby causing the defects in cell wall formation with a binding affinity that vary between cephalosporins (106). On the other hand, avibactam inactivates susceptible $\beta$-lactamases by serine-residue covalent acylation: avibactam, through in vitro studies, has shown an attractive activity vs. Ambler class A [e.g., ESBL and Klebsiella pneumoniae carbapenemase (KPC)], class C (e.g., AmpC), and some class D (e.g., OXA-48) enzymes $(107,108)$.
This new combined-cephalosporin offers an exceptional action to ESBL- and AmpC-producing Enterobacteriaceae comprising strains that allow the of both enzymes (109-112). This activity was confirmed in samples collected in studies from U.S. $(113,114)$ and European $(115)$ countries. One of the largest database, the INFORM (International Network For Optimal Resistance Monitoring) global surveillance study (116), has counted 34,062 isolates of Enterobacteriaceae from multiple sites and infections (e.g., IAI, UTI, SSTI, LRTI and bloodstream infections) in 176 medical centre laboratories from 39 countries): $99.5 \%$ of Enterobacteriaceae isolates were susceptible to $\mathrm{C} / \mathrm{A}$ with a $\mathrm{MIC} \leq 8 \mu \mathrm{g} / \mathrm{mL}$ (defined resistant to $\mathrm{MIC} \geq 16 \mu \mathrm{g} / \mathrm{mL}$ ) (115). Lately, it was designated as inhibitory mechanism rooted on a mutation of an AmpC alternate by removal of single amino acid and a lower affinity to $\mathrm{C} / \mathrm{A}$ in some Enterobacteriaceae cloacae extended-spectrum AmpC (ESAC) $\beta$-lactamase enzymes (116-118): despite that resistance due to AmpC variant has remained anecdotal.

$\mathrm{C} / \mathrm{A}$ has shown in vitro susceptibility rate up to $98 \%$ against KPC-producing $K$. pneumoniae isolates from most 
U.S. and European hospitals (119-123). Although only a few studies have differentiated activity of C/A against KPC subtypes, emerging data indicate that KPC-3producing strains have higher MICs than KPC-2 producers $(124,125)$. C/A-resistant strains among KPC-producing Enterobacteriaceae may appear due to mutations that increase ceftazidimase specificity rather than conferring avibactam resistance; nevertheless, its current medical significance remains undefined (119-123).

While in the year 2015, the first report on of $\mathrm{C} / \mathrm{A}$ resistance in a KPC-3-generating $\mathrm{K}$. pneumoniae was reported (123), and additional cases have been defined ever since $(124,125)$. Therefore, despite being a favourable remedy, C/A use should be cautious (126). For GNB, it has activity against strains generating class $\mathrm{D}$ carbapenemases as OXA-24 and OXA-48 (127), as well as OXA-40 and OXA-69 (128). Among PA strains, an examination of 3,902 aggregates from 75 U.S. clinical centres recognised that $96.9 \%$ of the strains were receptive to C/A (MIC $\leq 8 \mu \mathrm{g} / \mathrm{mL}$ ) (129). In the same survey, susceptibility to C/A for MDR and XDR Pseudomonas strains was $81.0 \%$ and $73.7 \%$, respectively. In 2017 , the same authors assessed 7,686 isolates from the same hospitals, confirming previous results (114). C/A has been compared with $\mathrm{C} / \mathrm{T}$ against $\mathrm{PA}$ with similar susceptibility percentages, but lower MIC for C/T $(55,114,130,131)$.

\section{Clinical trials for C/A in pneumonia}

C/A has previously proven its clinical efficacy for the treatment of severe GNB infections in phase III trials of cIAI and cUTI, receiving approval in both in the U.S. as well as in the European countries (104,105). Recently in a phase III, randomized, double-blind, double-dummy trial, the REPROVE study, investigators have proved the non-inferiority of C/A vs. meropenem in hospitalized adults with HAP/VAP due to GNB, including ceftazidime non-susceptible strains (C/A-NS) (25). Eligible patients, recruited for 24 countries, included hospitalized adults (aged 18-90 years) randomized 1:1 to receive either C/A $2.5 \mathrm{~g}(2.0 \mathrm{~g}$ ceftazidime plus $0.5 \mathrm{~g}$ avibactam, q8h IV over $2 \mathrm{~h}$ ) plus meropenem placebo or meropenem $1 \mathrm{~g}$ (q8h IV over 30 minutes) plus C/A placebo for 7 to 14 days (25). Additionally, from randomization, openlabel aminoglycosides, and linezolid or vancomycin were permitted while awaiting culture results for 24 to $72 \mathrm{~h}$ $(25,132-134)$. The primary endpoint in this study was clinical cure at the TOC visit with additional secondary endpoints, including all-cause 28-day mortality (25). In the ITT group, $69 \%$ of subjects in the C/A group were clinically treated at the TOC stay when compared to $73 \%$ in the meropenem group. At the same instance, $77 \%$ in the $\mathrm{C} / \mathrm{A}$ group and $78 \%$ in the meropenem group attained medical therapy in the sample population (25). All-cause fatality rates seemed to be $8 \%$ and $7 \%$ in the C/A and meropenem groups, respectively (25). This registration study has also placed some dubiousness about safety in the C/A group compared to meropenem, with reported higher rates of serious adverse reactions (19\% vs. 13\%) and adverse events leading to study drug discontinuation (4\% vs. 2.7\%) (132-134).

\section{Lung penetration of C/A}

From both, PK and PD modelling studies have resulted that $\mathrm{C} / \mathrm{A}$ at the standard dose $(2.5 \mathrm{~g}$ every $8 \mathrm{~h})$ infused over $2 \mathrm{~h}$, reached ELF's favourable concentrations (135). Analysis using a population PK model found that the proportion of the medicating interval that the free-drug absorption of $\mathrm{C} / \mathrm{A}$ rests above the MIC (\% $\mathrm{fT}>\mathrm{MIC})$ that is essential in leading to a favourable result in subjects with HAP was $>45 \%(135,136)$. Preclinical results in rats indicated that permeation of the medication in the lung is about $30 \%$ of the plasma absorption and PK/PD studies in individuals established the validity of preclinical data in animals (135-139). In terms of PK, the lung' penetration of C/A is just about $25-35 \%$ of the absorption in the plasma and was assessed in two phases I studies $(135,136)$. ELF penetration of $\mathrm{C} / \mathrm{A}$ is minor when compared to piperacillin $(40-50 \%)$ or meropenem (50\%) (136).

\section{Place in therapy of C/A within IMW}

Data from the REPROVE study $(25,132)$ have defined $\mathrm{C} / \mathrm{A}$ as a valid alternative to carbapenems in carbapenemresistant Enterobacteriaceae (CRE) nosocomial respiratory infections. Despite that, should be considered that patients in the clinical practice who are receiving $\mathrm{C} /$ A, might be frail, with several comorbidities $(133,134)$. De novo resistance and development of resistance during C/A therapy, are reported in literature (123-126). These reports increase the likelihood of a relatively low barrier to resistance for C/A and have important implications for antibiotic stewardship programs (123-126). Shields et al. (140) evaluated risk factors associated with $\mathrm{C} / \mathrm{A}$ failures and the development of resistance in a cohort of adults $(\mathrm{n}=77)$. Most failures have occurred in the pneumonia group (64\%), compared to patients with urinary tract infections and blood-stream infections who experienced 
higher success rates ( $88 \%$ and $75 \%$, respectively). Alongside pneumonia, renal replacement therapy was defined as independent predictors of clinical failures (140). Assuming the potential advantage of this new cephalosporin to treat CPE infections, discretion should be implemented to bound the extensive use of $\mathrm{C} / \mathrm{A}$ for culture-negative infections or when more narrow-spectrum antibiotics are still active (141). C/A with its broad activity against ESBLs and chromosomal Amp-producing Enterobacteriaceae may be a practical choice to spare carbapenems in these fields (Table 1). Despite the placing on the market of C/T, C/A should not be forgotten in the management of PA pneumonia $(142,143)$. Furthermore, clinical studies with C/A in MDR/XDR PA infections are scarce and contain low numbers of patients: the cure rates were close to $80 \%$, and most failures occurred in respiratory tract infections $(144,145)$.

\section{Ceftaroline}

Ceftaroline is a novel generation cephalosporin distinguished by a particular spectrum of activity on common bacterial causes of CAP $(21,22)$. In the US, because of failure of the approval of ceftobiprole for CAP, is at the moment the only anti-MRSA cephalosporins available for LRTIs (146).

\section{Antimicrobial properties of ceftaroline}

Ceftaroline spreads its antimicrobial activity by specifically binding of PBPs, notably to the PBP2a, an MRSA-specific protein that has low affinity for most other $\beta$-lactam antibacterials (147).

Among Staphylococcus spp. strains, by comparing ceftaroline and ceftriaxone, the first has resulted more potent in both instances, against MSSA ( $\geq 16$-fold) and MRSA ( $\geq 32$-fold) (148).

Moreover, susceptibility rates for ceftaroline against MRSA isolates were reported broadly high (between 68.2\% to $93.6 \%$ ) but changeable between states and regions, with a more favourable profile in European than in Asian or South American countries (149-154).

Ceftaroline also retains an attractive spectrum of activity on other Gram-positive bacteria, notably vancomycinintermediate Staphylococcus aureus (VISA), heterogeneous VISA (hVISA), vancomycin-resistant Staphylococcus aureus (VRSA) or daptomycin non-susceptible $S$. aureus, linezolidresistant $S$. aureus, MR-CoNS and Streptococci, including MDR S. pneumoniae (149-152).

Among S. pneumoniae strains, ceftaroline was comparable to ceftriaxone in the treatment of penicillin-susceptible strains but more effective in a subject infected by MDR S. pneumoniae strains (150-153). Ceftaroline susceptibility in the AWARE program among penicillin-resistant Streptococcus pneumoniae ranged from $77.4 \%$ to $100 \%$ (154)

Ceftaroline also exhibits potent in vitro activity against GNB, including Haemophilus spp., Moraxella catarrbalis, Morganella morganii and not-ESBL or AmpC-producing Enterobacteriaceae (150-153).

\section{Clinical trials for ceftaroline in pneumonia}

Ceftaroline was approved for the treatment of CAP according to FOCUS $1 \& 2$ studies, two phases III randomized controlled trials (RCTs) $(21,22)$. Both studies were conducted in an adult population with radiologically confirmed moderate-to-severe CAP comparing ceftaroline $(600 \mathrm{mg} \mathrm{q} 12 \mathrm{~h})$ vs. ceftriaxone (1 g q24h), with an additionally empiric macrolide (on day 1 ) within-subjects enrolled in FOCUS 1, for atypical pathogen coverage. Subsequently, in Asian subjects was performed, a phase III, non-inferiority with nested superiority trial, using ceftriaxone $2 \mathrm{~g} \mathrm{q} 24 \mathrm{~h}$ as a comparator (155). Of note, in all these studies patients with a definite diagnosis of MRSA or high-risk subjects for MRSA infection were excluded, owing to the inactivity of ceftriaxone against these strains (155).

In both FOCUS $1 \& 2(21,22)$, ceftaroline showed a proper safety and efficacy, achieving non-inferiority to the comparator in the co-primary modified ITT efficacy and clinically evaluable populations for the primary endpoint of clinical cure at the TOC visit. In the unified examination of FOCUS 1 and FOCUS 2, clinical cure rates for patients with MSSA CAP at the TOC appointment in the microbiological reformed ITT efficiency inhabitants were $72 \%$ (18 of 25 ) with ceftaroline fosamil, related with $60 \%$ (18 of 30) for ceftriaxone $(21,22,155)$. With ceftaroline, the clinical cure was achieved in up to $80 \%$ of cases and was still associated with a shorter time to clinical response than ceftriaxone.

The combined examination of FOCUS 1 and FOCUS 2 providing a well-being data set of 1,228 patients, with ceftaroline fosamil representing an encouraging well-being and tolerability profile, as predictable for a cephalosporin, with similar rates of adverse events for ceftaroline fosamil $(47.0 \%)$ and ceftriaxone $(45.7 \%)(21,22,155)$.

\section{Lung penetration of ceftaroline}

ELF penetration of ceftaroline was assessed in a phase I study among fifty-three healthy subjects at different 
dosing (600 mg, bid and $600 \mathrm{mg}$, tid) for which free lung ceftaroline was approximatively $23 \%(22.5 \%$ and $23.6 \%$, respectively in the groups) and analogous to other $\beta$-lactams (156). In a staphylococcal murine pneumonia model, Riccobene et al. have demonstrated that absorption of ceftaroline in ELF in a human model was comparable to serum absorption, causing in similar $\mathrm{fT}>\mathrm{MIC}$ values in serum and ELF: the dissemination of free ceftaroline into ELF, was $23 \%$ (156). Furthermore, they have reported that ceftaroline promptly infiltrating into ELF with maximum concentrations occurring at the end of infusion (156).

Employing plasma and ELF exposure data, stimulated that were evaluated to achieve fT $>$ MIC goals of $42.0 \%$ for plasma and $17.0 \%$ for ELF (156-158) in a staphylococcal murine-pneumonia model. For ceftaroline $600 \mathrm{mg} \mathrm{q} 12 \mathrm{~h}$, $98.1 \%$ of counterfeit patients acquired a $42.0 \%$ fT $>1 \mathrm{mg} / \mathrm{L}$ in plasma, and $81.7 \%$ also attained a $17.0 \% \mathrm{fT}>1 \mathrm{mg} / \mathrm{L}$ in ELF (156,157). For ceftaroline fosamil $600 \mathrm{mg} \mathrm{q} 8 \mathrm{~h}, 100 \%$ and $94.7 \%$ of simulated patients achieved the respective plasma and ELF targets (156-158).

\section{Place in therapy of ceftaroline within IMWs}

Ceftaroline unites in itself a high bactericidal activity against a wide spectrum of pathogens involved in pneumonia (149-151) with a favourable posology: 5 to 7 days of twice-a-day administration schedule is recommended in patients with CAP $(21,22,152)$. Ecological impact of ceftaroline on gut and microbiota is less known, theoretically minimal due to low faecal excretion. Differences in metabolism and excretion, have identified ceftaroline as a good alternative in patients who complain a biliary tract disease with at risk for pseudo-cholelithiasis. Ceftaroline is a desirable option in a patient admitted for CAP, with high risk for MRSA or previously known colonization and haematologic features of chronic anaemia or low platelets, in which treatment with a valid molecule such linezolid may increase the risk of bone marrow hyporegeneration (Figure 1) $(15,28)$. Furthermore, ceftaroline is a favourable option in Staphylococcalpneumonia, according to its higher ELF penetration than glycopeptides and low risk of nephrotoxicity. Staphylococcus-related pneumonia might be secondary to a previous or current bacteremia, as reported for central venous catheter (CVC) related bloodstream infections or infectious endocarditis: involvement of the lungs, as multifocal pneumonia spreading from septic embolism, could be in the presence of specific interest of this extendedspectrum cephalosporin $(15,28,159,160)$.
Ceftaroline as for ceftobiprole may be first-line agents, flanked by neuraminidase inhibitors, in severe CAP complicating influenza for their known anti-MRSA activity (Figure 1) $(15,28,159-162)$.

\section{Conclusions}

The arrival of new cephalosporins has helped to reach some niche populations, otherwise difficult to access (e.g., postflu pneumonia, PA pneumonia, CRE pneumonia) and to give valid alternatives to the previously known antibiotics in this field. Ceftobiprole and ceftaroline provide valuable benefits against MRSA and MDR S. pneumoniae avoiding combination, flanked by a stimulating spectrum on GNB (including PA for ceftobiprole). Furthermore, ceftobiprole and ceftaroline may guarantee a low rate of adverse events and very restricted drug-to-drug interactions during treatment of LRTIs, also in frail patients. C/T and C/A are a useful weapon in pneumonia due to MDR PA, CRE and ESBL-producing Enterobacteriaceae. C/T and C/A are valid alternatives to spare carbapenems, notably when carbapenems are not well tolerated, in empiric and targeted treatments in this field.

Pivotal in the use of this new cephalosporins is to describe and define better the features of the patient by assessing the risk of MRSA or MDR GNB colonization, underlying lung abnormalities or systemic diseases, the grade of severity of pneumonia, risk of adverse events or drug-related toxicity. In other words, currently, the approach to pneumonia infection must be targeted to the individual based on the clinical situation, the intrinsic host characteristic, the susceptibility profile, and local epidemiology and the "universal pneumonia antibiotic strategy" is no longer acceptable for treating lung infections.

\section{Acknowledgments}

Funding: None.

\section{Footnote}

Conflicts of Interest: All authors have completed the ICMJE uniform disclosure form (available at http://dx.doi. org/10.21037/jtd-20-417). FGDR and SC were speaker for Pfizer, MSD and Correvio, FGDR was part of advisory board for Pfizer, MSD. The other authors have no conflicts of interest to declare. 
Ethical Statement: The authors are accountable for all aspects of the work in ensuring that questions related to the accuracy or integrity of any part of the work are appropriately investigated and resolved.

Open Access Statement: This is an Open Access article distributed in accordance with the Creative Commons Attribution-NonCommercial-NoDerivs 4.0 International License (CC BY-NC-ND 4.0), which permits the noncommercial replication and distribution of the article with the strict proviso that no changes or edits are made and the original work is properly cited (including links to both the formal publication through the relevant DOI and the license). See: https://creativecommons.org/licenses/by-nc-nd/4.0/.

\section{References}

1. Versporten A, Zarb P, Caniaux I, et al. Antimicrobial consumption and resistance in adult hospital inpatients in 53 countries: results of an internet-based global point prevalence survey. Lancet Glob Health 2018;6:e619-29.

2. Feldman C, Anderson R. Pneumonia as a systemic illness. Curr Opin Pulm Med 2018;24:237-43.

3. Eurich DT, Marrie TJ, Minhas-Sandhu JK, et al. Tenyear mortality after community-acquired pneumonia. A prospective cohort. Am J Respir Crit Care Med 2015;192:597-604.

4. Hayes BH, Haberling DL, Kennedy JL, et al. Burden of pneumonia-associated hospitalizations: United States. Chest 2018;153:427-37.

5. Venditti M, Falcone M, Corrao S, et al. Outcomes of patients hospitalized with community-acquired, health care-associated, and hospital-acquired pneumonia. Ann Intern Med 2009;150:19-26.

6. Riccioni G, Di Pietro V, Staniscia T, et al. Community acquired pneumonia in internal medicine: a one-year retrospective study based on pneumonia severity index. Int J Immunopathol Pharmacol 2005;18:575-86.

7. Giannelli G, Minchella L, Lopalco PL, et al. Treatment of community-acquired pneumonia: a descriptive study in an Apulian department of internal medicine. Med Sci Monit 2005;11:CR434-CR439.

8. Marrie TJ, Carriere KC, Jin Y, et al. Mortality during hospitalization for pneumonia in Alberta, Canada, is associated with physician volume. Eur Respir J 2003;22:148-55

9. Blasi F, Iori I, Bulfoni A, et al. Can CAP guideline adherence improve patient outcome in internal medicine departments? Eur Respir J 2008;32:902-10.

10. Martínez D, Alvarez Rodriguez V, Ortiz de Zarate MM, et al. Management in the emergency room of patients requiring hospital treatment of community acquired pneumonia. Rev Esp Quimioter 2009;22:4-9.

11. Etzion O, Novack V, Avnon L, et al. Characteristics of low-risk patients hospitalized with community-acquired pneumonia. Eur J Intern Med 2007;18:209-14.

12. Bouza E, Giannella M, Pinilla B, et al. The management of pneumonia in internal medicine. Rev Clin Esp 2013;213:298-305.

13. Cillóniz C, Rodríguez-Hurtado D, Torres A. Characteristics and Management of Community-Acquired Pneumonia in the Era of Global Aging. Med Sci (Basel) 2018;6:35.

14. Muscedere JG, Day A, Heyland DK. Mortality, attributable mortality, and clinical events as end points for clinical trials of ventilatorassociated pneumonia and hospital-acquired pneumonia. Clin Infect Dis 2010;51:S120-5.

15. Liapikou A, Cilloniz C, Palomeque A, et al. Emerging antibiotics for community-acquired pneumonia. Expert Opin Emerg Drugs 2019;24:221-31. Erratum in: Correction. Expert Opin Emerg Drugs 2019;24:i.

16. Goo KS, Sim TS. Designing new $\beta$-lactams: implications from their targets, resistance factors and synthesizing enzymes. Curr Comput Aided Drug Des 2011;7:53-80.

17. Viasus D, Vecino-Moreno M, De La Hoz JM, et al. Antibiotic stewardship in community-acquired pneumonia. Expert Rev Anti Infect Ther 2017;15:351-9.

18. Cillóniz C, Dominedò C, Torres A. Multidrug resistant gram-negative bacteria in community-acquired pneumonia. Crit Care 2019;23:79.

19. Nicholson SC, Welte T, File TM Jr, et al. A randomised, double-blind trial comparing ceftobiprole medocaril with ceftriaxone with or without linezolid for the treatment of patients with community-acquired pneumonia requiring hospitalisation. Int J Antimicrob Agents 2012;39:240-6.

20. Awad SS, Rodriguez AH, Chuang YC, et al. A phase 3 randomized double-blind comparison of ceftobiprole medocaril vs. ceftazidime plus linezolid for the treatment of hospital-acquired pneumonia. Clin Infect Dis 2014;59:51-61.

21. File TM Jr, Low DE, Eckburg PB, et al. FOCUS 1: a randomized, double-blinded, multicentre, Phase III trial of the efficacy and safety of ceftaroline fosamil versus ceftriaxone in community-acquired pneumonia. $\mathrm{J}$ Antimicrob Chemother 2011;66:iii19-32.

22. Low DE, File TM Jr, Eckburg PB, et al. FOCUS 2: 
a randomized, double-blinded, multicentre, Phase III trial of the efficacy and safety of ceftaroline fosamil versus ceftriaxone in community-acquired pneumonia. J Antimicrob Chemother 2011;66:iii33-44.

23. Kollef MH, Nováček M, Kivistik Ü, et al. Ceftolozanetazobactam versus meropenem for treatment of nosocomial pneumonia (ASPECT-NP): a randomised, controlled, double-blind, phase 3, non-inferiority trial. Lancet Infect Dis 2019;19:1299-311.

24. Koulenti D, Lisboa T, Brun-Buisson C, et al. EU-VAP/ CAP Study Group. Spectrum of practice in the diagnosis of nosocomial pneumonia in patients requiring mechanical ventilation in European intensive care units. Crit Care Med 2009;37:2360-8.

25. Torres A, Zhong N, Pachl J, et al. Ceftazidime-avibactam versus meropenem in nosocomial pneumonia, including ventilator-associated pneumonia (REPROVE): A randomised, double-blind, phase 3 non-inferiority trial. Lancet Infect Dis 2018;18:285-95.

26. Wright H, Bonomo RA, Paterson DL. New agents for the treatment of infections with Gram-negative bacteria: restoring the miracle or false dawn? Clin Microbiol Infect 2017;23:704-12.

27. Welte T, Torres A, Nathwani D. Clinical and economic burden of community-acquired pneumonia among adults in Europe. Thorax 2012;67:71-9.

28. Welte T, Kantecki M, Stone GG, et al. Ceftaroline fosamil as a potential treatment option for Staphylococcus aureus community-acquired pneumonia in adults. Int J Antimicrob Agents 2019;54:410-22.

29. Jain S, Self WH, Wunderink RG, et al. Communityacquired pneumonia requiring hospitalization among U.S. adults. N Engl J Med 2015;373:415-27.

30. Self WH, Wunderink RG, Williams DJ, et al. Staphylococcus aureus community-acquired pneumonia: prevalence, clinical characteristics, and outcomes. Clin Infect Dis 2016;63:300-9.

31. Falcó V, Burgos J, Almirante B. Ceftobiprole medocaril for the treatment of community-acquired pneumonia. Expert Opin Pharmacother 2018;19:1503-9.

32. Amalakuhan B, Echevarria KL, Restrepo MI. Managing community acquired pneumonia in the elderly - the next generation of pharmacotherapy on the horizon. Expert Opin Pharmacother 2017;18:1039-48.

33. Allou N, Kermarrec N, Muller C, et al. Risk factors and prognosis of post-operative pneumonia due to Pseudomonas aeruginosa following cardiac surgery. J Antimicrob Chemother 2010;65:806-7.
34. Torres A, Ewig S, Lode H, et al. Defining, treating and preventing hospital acquired pneumonia: European perspective. Intensive Care Med 2009;35:9-29.

35. Montravers P, Harpan A, Guivarch E. Current and Future Considerations for the Treatment of Hospital-Acquired Pneumonia. Adv Ther 2016;33:151-66.

36. Carbonne H, Le Dorze M, Bourrel AS, et al. Relation between presence of extended-spectrum $\beta$-lactamaseproducing Enterobacteriaceae in systematic rectal swabs and respiratory tract specimens in ICU patients. Ann Intensive Care 2017;7:13.

37. Goulenok T, Ferroni A, Bille E, et al. Risk factors for developing ESBL E. coli: can clinicians predict infection in patients with prior colonization? J Hosp Infect 2013;84:294-9.

38. Wagenlehner FM, Umeh O, Steenbergen J, et al. Ceftolozane-tazobactam compared with levofloxacin in the treatment of complicated urinary-tract infections, including pyelonephritis: a randomised, double-blind, phase 3 trial (ASPECT-cUTI). Lancet 2015;385:1949-56.

39. Solomkin J, Hershberger E, Miller B, et al. Ceftolozane/ tazobactam plus metronidazole for complicated intraabdominal infections in an era of multidrug resistance: results from a randomized, double-blind, phase 3 trial (ASPECT-cIAI). Clin Infect Dis 2015;60:1462-71.

40. U.S. Food and Drug Administration. Zerbaxa ®. Full prescribing information. Available online: https://www. accessdata.fda.gov/drugsatfda_docs/label/2014/206829lbl.pdf

41. European Medicines Agency. Zerbaxa ®. Annex I. Summary of product characteristics. Available online: http://www.ema.europa.eu/docs/en_GB/document_ library/EPAR_Product_Information/human/003772/ WC500194595.pdf

42. Hong MC, Hsu DI, Bounthavong M. Ceftolozane/ tazobactam: a novel antipseudomonal cephalosporin and $\beta$-lactamase-inhibitor combination. Infect Drug Resist 2013;6:215-23.

43. Cluck D, Lewis P, Stayer B, et al. Ceftolozane-tazobactam: A new generation cephalosporin. Am J Health Syst Pharm 2015;72:2135-46.

44. Farrell DJ, Sader HS, Flamm RK, et al. Ceftolozane/ tazobactam activity tested against Gram-negative bacterial isolates from hospitalised patients with pneumonia in US and European medical centres (2012). Int J Antimicrob Agents 2014;43:533-9.

45. Riera $\mathrm{E}$, Macià $\mathrm{MD}$, Mena $\mathrm{A}$, et al. Anti-biofilm and resistance suppression activities of CXA-101 against chronic respiratory infection phenotypes of Pseudomonas 
aeruginosa strain PAO1. J Antimicrob Chemother 2010;65:1399-404.

46. Velez Perez AL, Schmidt-Malan SM, Kohner PC, et al. In vitro activity of ceftolozane/tazobactam against clinical isolates of Pseudomonas aeruginosa in the planktonic and biofilm states. Diagn Microbiol Infect Dis 2016;85:356-9.

47. Moyá B, Zamorano L, Juan C, et al. Affinity of the new cephalosporin CXA-101 to penicillin-binding proteins of Pseudomonas aeruginosa. Antimicrob Agents Chemother 2010;54:3933-7.

48. Murano K, Yamanaka T, Toda A, et al. Structural requirements for the stability of novel cephalosporins to AmpC beta-lactamase based on 3D-structure. Bioorg Med Chem 2008;16:2261-75.

49. Takeda S, Ishii Y, Hatano K, et al. Stability of FR264205 against AmpC beta-lactamase of Pseudomonas aeruginosa. Int J Antimicrob Agents 2007;30:443-5.

50. Moyá B, Beceiro A, Cabot G, et al. Pan- $\beta$-lactam resistance development in Pseudomonas aeruginosa clinical strains: molecular mechanisms, penicillin-binding protein profiles, and binding affinities. Antimicrob Agents Chemother 2012;56:4771-8.

51. Castanheira M, Mills JC, Farrell DJ, et al. Mutationdriven $\beta$-lactam resistance mechanisms among contemporary ceftazidime-nonsusceptible Pseudomonas aeruginosa isolates from U.S. hospitals. Antimicrob Agents Chemother 2014;58:6844-50.

52. Moyá B, Zamorano L, Juan C, et al. Activity of a new cephalosporin, CXA-101 (FR264205), against beta-lactamresistant Pseudomonas aeruginosa mutants selected in vitro and after antipseudomonal treatment of intensive care unit patients. Antimicrob Agents Chemother 2010;54:1213-7.

53. Zilberberg MD, Shorr AF. Prevalence of multidrugresistant Pseudomonas aeruginosa and carbapenemresistant Enterobacteriaceae among specimens from hospitalized patients with pneumonia and bloodstream infections in the United States from 2000 to 2009. J Hosp Med 2013;8:559-63.

54. Sader HS, Castanheira M, Duncan LR, et al. Antimicrobial susceptibility of Enterobacteriaceae and Pseudomonas aeruginosa isolates from United States medical centers stratified by infection type: results from the International Network for Optimal Resistance Monitoring (INFORM) surveillance program, 2015-2016. Diagn Microbiol Infect Dis 2018;92:69-74.

55. Grupper M, Sutherland C, Nicolau DP. Multicenter Evaluation of Ceftazidime-Avibactam and CeftolozaneTazobactam Inhibitory Activity against Meropenem-
Nonsusceptible Pseudomonas aeruginosa from Blood, Respiratory Tract, and Wounds. Antimicrob Agents Chemother 2017;61:e00875-17.

56. Humphries RM, Hindler JA, Wong-Beringer A, et al. Activity of Ceftolozane-Tazobactam and CeftazidimeAvibactam against Beta-Lactam-Resistant Pseudomonas aeruginosa Isolates. Antimicrob Agents Chemother 2017;61:e01858-17.

57. Pogue JM, Kaye KS, Veve MP, et al. Ceftolozane/ Tazobactam vs Polymyxin or Aminoglycosidebased Regimens for the Treatment of Drug-resistant Pseudomonas Aeruginosa. Clin Infect Dis 2019;ciz816. [Epub ahead of print]. doi: 10.1093/cid/ciz816.

58. Gallagher JC, Satlin MJ, Elabor A, et al. Ceftolozanetazobactam for the treatment of multidrug-resistant pseudomonas aeruginosa infections: a multicenter study. Open Forum Infect Dis 2018;5:ofy280.

59. Bassetti M, Castaldo N, Cattelan A, et al. CEFTABUSE Study Group. Ceftolozane/ tazobactam for the treatment of serious Pseudomonas aeruginosa infections: a multicentre nationwide clinical experience. Int J Antimicrob Agents 2019;53:408-15.

60. Gelfand MS, Cleveland KO. Ceftolozane/Tazobactam Therapy of Respiratory Infections due to MultidrugResistant Pseudomonas aeruginosa. Clin Infect Dis 2015;61:853-5.

61. Giacobbe DR, Bassetti M, De Rosa FG, et al. Ceftolozane/ tazobactam: place in therapy. Expert Rev Anti Infect Ther 2018;16:307-20.

62. Kalil AC, Zavascki AP. Can ceftolozane-tazobactam treat nosocomial pneumonia? Lancet Infect Dis 2019;19:1266-7.

63. Chandorkar G, Huntington JA, Gotfried MH, et al. Intrapulmonary penetration of ceftolozane/tazobactam and piperacillin/tazobactam in healthy adult subjects. J Antimicrob Chemother 2012;67:2463-9.

64. Melchers MJ, Mavridou E, Seyedmousavi S, et al. Plasma and epithelial lining fluid pharmacokinetics of ceftolozane and tazobactam alone and in combination in mice. Antimicrob Agents Chemother 2015;59:3373-6.

65. Xiao AJ, Miller BW, Huntington JA, et al. Ceftolozane/ tazobactam pharmacokinetic/pharmacodynamic-derived dose justification for phase 3 studies in patients with nosocomial pneumonia. J Clin Pharmacol 2016;56:56-66.

66. Detsis M, Karanika S, Mylonakis E. ICU Acquisition Rate, Risk Factors, and Clinical Significance of Digestive Tract Colonization With Extended-Spectrum Beta-Lactamase Producing Enterobacteriaceae: A Systematic Review and Meta-Analysis. Crit Care Med 2017;45:705-14. 
67. Ruppé E, Armand-Lefèvre L, Estellat C, et al. High Rate of Acquisition but Short Duration of Carriage of Multidrug-Resistant Enterobacteriaceae After Travel to the Tropics. Clin Infect Dis 2015;61:593-600.

68. Pilmis B, Cattoir V, Lecointe D, et al. Carriage of ESBLproducing Enterobacteriaceae in French hospitals: the PORTABLSE study. J Hosp Infect 2018;98:247-52.

69. Kalil AC, Metersky ML, Klompas M, et al. Management of adults with hospitalacquired and ventilator-associated pneumonia: 2016 Clinical Practice Guidelines by the Infectious Diseases Society of America and the American Thoracic Society. Clin Infect Dis 2016;63:e61-111.

70. Corcione S, Lupia T, Maraolo AE, et al. Carbapenemsparing strategy: carbapenemase, treatment, and stewardship. Curr Opin Infect Dis 2019;32:663-73.

71. Restrepo MI, Babu BL, Reyes LF, et al. Burden and risk factors for Pseudomonas aeruginosa community-acquired pneumonia: a multinational point prevalence study of hospitalized patients. Eur Respir J 2018;52:1701190.

72. Bassetti M, Vena A, Croxatto A, et al. How to manage Pseudomonas aeruginosa infections. Drugs Context 2018;7:212527.

73. Noel GJ, Bush K, Bagchi P, et al. A randomized, doubleblind trial comparing ceftobiprole medocaril with vancomycin plus ceftazidime for the treatment of patients with complicated skin and skin-structure infections. Clin Infect Dis 2008;46:647-55.

74. Davies TA, Page MG, Shang W, et al. Binding of ceftobiprole and comparators to the penicillin-binding proteins of Escherichia coli, Pseudomonas aeruginosa, Staphylococcus aureus, and Streptococcus pneumoniae. Antimicrob Agents Chemother 2007;51:2621-4.

75. Hebeisen P, Heinze-Krauss I, Angehrn P, et al. In vitro and in vivo properties of Ro 63-9141, a novel broadspectrum cephalosporin with activity against methicillinresistant staphylococci. Antimicrob Agents Chemother 2001;45:825-36.

76. Lovering AL, Gretes MC, Safadi SS, et al. Structural insights into the anti-methicillin-resistant Staphylococcus aureus (MRSA) activity of ceftobiprole. J Biol Chem 2012;287:32096-102.

77. Queenan AM, Shang W, Kania M, et al. Interactions of ceftobiprole with beta-lactamases from molecular classes A to D. Antimicrob Agents Chemother 2007;51:3089-95.

78. Zbinden R, Punter V, von Graevenitz A. In vitro activities of BAL9141, a novel broad-spectrum pyrrolidinone cephalosporin, against gram negative nonfermenters. Antimicrob Agents Chemother 2002;46:871-4.
79. Jones RN, Deshpande LM, Mutnick AH, et al. In vitro evaluation of BAL9141, a novel parenteral cephalosporin active against oxacillin resistant staphylococci. J Antimicrob Chemother 2002;50:915-32.

80. Bal AM, David MZ, Garau J, et al. Future trends in the treatment of methicillin-resistant Staphylococcus aureus (MRSA) infection: an indepth review of newer antibiotics active against an enduring pathogen. J Glob Antimicrob Resist 2017;10:295-303.

81. Fritsche TR, Sader HS, Jones RN. Antimicrobial activity of ceftobiprole, a novel anti-methicillin-resistant Staphylococcus aureus cephalosporin, tested against contemporary pathogens: results from the SENTRY Antimicrobial Surveillance Program (2005-2006). Diagn Microbiol Infect Dis 2008;61:86-95.

82. Davies TA, Flamm RK, Lynch AS. Activity of ceftobiprole against Streptococcus pneumoniae isolates exhibiting highlevel resistance to ceftriaxone. Int J Antimicrob Agents 2012;39:534-8.

83. Farrell DJ, Flamm RK, Sader HS, et al. Ceftobiprole activity against over 60,000 clinical bacterial pathogens isolated in Europe, Turkey, and Israel from 2005 to 2010. Antimicrob Agents Chemother 2014;58:3882-8.

84. Pfaller MA, Flamm RK, Duncan LR, et al. Antimicrobial activity of ceftobiprole and comparator agents when tested against contemporary Gram-positive and -negative organisms collected from Europe (2015). Diagn Microbiol Infect Dis 2018;91:77-84.

85. Pfaller MA, Flamm RK, Mendes RE, et al. Ceftobiprole activity against Gram-positive and -negative pathogens collected from in the United States in 2006 and 2016. Antimicrob Agents Chemother 2018;63:1.

86. Rossolini GM, Dryden MS, Kozlov RS, et al. Comparative activity of ceftobiprole against Gram-positive and Gramnegative isolates from Europe and the Middle East: the CLASS study. J Antimicrob Chemother 2011;66:151-9.

87. Santerre Henriksen A, Smart JI, Hamed K. Susceptibility to ceftobiprole of respiratory-tract pathogens collected in the United Kingdom and Ireland during 2014-2015. Infect Drug Resist 2018;11:1309-20.

88. Pillar CM, Aranza MK, Shah D, et al. In vitro activity profile of ceftobiprole, an anti-MRSA cephalosporin, against recent Grampositive and gram-negative isolates of European origin. J Antimicrob Chemother 2008;61:595-602.

89. Abbanat D, Shang W, Amsler K, et al. Evaluation of the in vitro activities of ceftobiprole and comparators in staphylococcal colony or microtitre plate biofilm assays. Int J Antimicrob Agents 2014;43:32-9. 
90. Walkty A, Adam HJ, Laverdiere M, et al. In vitro activity of ceftobiprole against frequently encountered aerobic and facultative Gram-positive and Gram-negative bacterial pathogens: results of the CANWARD 2007-2009 study. Diagn Microbiol Infect Dis 2011;69:348-55.

91. Kresken M, Korber-Irrgang B, Lauffer J, et al. In vitro activities of ceftobiprole combined with amikacin or levofloxacin against Pseudomonas aeruginosa: evidence of a synergistic effect using time-kill methodology. Int J Antimicrob Agents 2011;38:70-5.

92. Giacobbe DR, De Rosa FG, Del Bono V, et al. Ceftobiprole: drug evaluation and place in therapy. Expert Rev Anti Infect Ther 2019;17:689-98.

93. Cillóniz C, Dominedò C, Garcia-Vidal C, et al. Ceftobiprole for the treatment of pneumonia. Rev Esp Quimioter 2019;32 Suppl 3:17-23.

94. Torres A, Mouton JW, Pea F. Pharmacokinetics and Dosing of Ceftobiprole Medocaril for the Treatment of Hospital- and Community-Acquired Pneumonia in Different Patient Populations. Clin Pharmacokinet 2016;55:1507-20.

95. Rodvold KA, Nicolau DP, Lodise TP, et al. Identifying exposure targets for treatment of staphylococcal pneumonia with ceftobiprole. Antimicrob Agents Chemother 2009;53:3294-301.

96. Kiem S, Schentag JJ. Interpretation of antibiotic concentration ratios measured in epithelial lining fluid. Antimicrob Agents Chemother 2008;52:24-36.

97. Rodvold KA, George JM, Yoo L. Penetration of antiinfective agents into pulmonary epithelial lining fluid: focus on antibacterial agents. Clin Pharmacokinet 2011;50:637-64.

98. Scheeren TWL, Welte T, Saulay M, et al. Early improvement in severely ill patients with pneumonia treated with ceftobiprole: a retrospective analysis of two major trials. BMC Infect Dis 2019;19:195.

99. Alberg AJ, Brock MV, Samet JM. Epidemiology of lung cancer: looking to the future. J Clin Oncol 2005;23:3175-85.

100. Rolston KVI, Nesher L. Post-Obstructive Pneumonia in Patients with Cancer: A Review. Infect Dis Ther 2018;7:29-38.

101. Torres A, Niederman MS, Chastre J, et al. International ERS/ESICM/ESCMID/ALAT guidelines for the management of hospital-acquired pneumonia and ventilator-associated pneumonia: Guidelines for the management of hospital-acquired pneumonia (HAP)/ ventilator-associated pneumonia (VAP) of the European Respiratory Society (ERS), European Society of Intensive
Care Medicine (ESICM), European Society of Clinical Microbiology and Infectious Diseases (ESCMID) and Asociación Latinoamericana del Tórax (ALAT). Eur Respir J 2017;50:1700582.

102. Rodríguez-Baño J, Gutiérrez-Gutiérrez B, Machuca I, et al. Treatment of Infections Caused by Extended-SpectrumBeta-Lactamase-, AmpC-, and Carbapenemase-Producing Enterobacteriaceae. Clin Microbiol Rev 2018;31:e00079-17.

103. Tuon FF, Rocha JL, Formigoni-Pinto MR.

Pharmacological aspects and spectrum of action of ceftazidime-avibactam: a systematic review. Infection 2018;46:165-81.

104.Mazuski JE, Gasink LB, Armstrong J, et al. Efficacy and safety of ceftazidime-avibactam plus metronidazole versus meropenem in the treatment of complicated intra-abdominal infection: results from a randomized, controlled, double-blind, phase 3 program. Clin Infect Dis 2016;62:1380-9.

105. Carmeli Y, Armstrong J, Laud PJ, et al. Ceftazidimeavibactam or best available therapy in patients with ceftazidime-resistant Enterobacteriaceae and Pseudomonas aeruginosa complicated urinary tract infections or complicated intra-abdominal infections (REPRISE): a randomised, pathogen-directed, phase 3 study. Lancet Infect Dis 2016;16:661-73.

106. Shirley M. Ceftazidime-Avibactam: A Review in the Treatment of Serious Gram-Negative Bacterial Infections. Drugs 2018;78:675-92.

107. Bonnefoy A, Dupuis-Hamelin C, Steier V, et al. In vitro activity of AVE1330A, an innovative broad-spectrum nonb-lactam blactamase inhibitor. J Antimicrob Chemother 2004;54:410-7.

108. Ehmann DE, Jahić H, Ross PL, et al. Avibactam is a covalent, reversible, non- $\beta$-lactam $\beta$-lactamase inhibitor. Proc Natl Acad Sci U S A 2012;109:11663-8.

109. Lagacé-Wiens P, Walkty A, Karlowsky JA. Ceftazidimeavibactam: an evidence-based review of its pharmacology and potential use in the treatment of Gram-negative bacterial infections. Core Evid 2014;9:13-25.

110. MacVane SH, Crandon JL, Nichols WW, et al. In vivo efficacy of humanized exposures of ceftazidime-avibactam in comparison with ceftazidime against contemporary Enterobacteriaceae isolates. Antimicrob Agents Chemother 2014;58:6913-9.

111. MacVane SH, Crandon JL, Nichols WW, et al. Unexpected in vivo activity of ceftazidime alone and in combination with avibactam against New Delhi metallobeta-lactamase-producing Enterobacteriaceae in a murine 
thigh infection model. Antimicrob Agents Chemother 2014;58:7007-9.

112.Li H, Estabrook M, Jacoby GA, et al. In vitro susceptibility of characterized beta-lactamase-producing strains tested with avibactam combinations. Antimicrob Agents Chemother 2015;59:1789-93.

113. Castanheira M, Farrell SE, Krause KM, et al. Contemporary diversity of beta-lactamases among Enterobacteriaceae in the nine US census regions and ceftazidimeavibactam activity tested against isolates producing the most prevalent beta-lactamase groups. Antimicrob Agents Chemother 2014;58:833-8.

114. Sader HS, Castanheira M, Shortridge D, et al. Antimicrobial Activity of Ceftazidime-Avibactam Tested against Multidrug-Resistant Enterobacteriaceae and Pseudomonas aeruginosa Isolates from U.S. Medical Centers, 2013 to 2016. Antimicrob Agents Chemother 2017;61:e01045-17.

115.López-Hernández I, Alonso N, Fernandez-Martinez M, et al. Activity of ceftazidime-avibactam against multidrugresistance Enterobacteriaceae expressing combined mechanisms of resistance. Enferm Infecc Microbiol Clin 2017;35:499-504.

116. Karlowsky JA, Biedenbach DJ, Kazmierczak KM, et al. Activity of ceftazidime-avibactam against extendedspectrum- and AmpC beta-lactamase-producing Enterobacteriaceae collected in the INFORM global surveillance study from 2012 to 2014. Antimicrob Agents Chemother 2016;60:2849-57.

117.Porres-Osante N, Dupont H, Torres C, et al. Avibactam activity against extendedspectrum $\mathrm{AmpC}$ beta-lactamases. J Antimicrob Chemother 2014;69:1715-6.

118. Lahiri SD, Giacobbe RA, Johnstone MR, et al. Activity of avibactam against Enterobacter cloacae producing an extendedspectrum class C beta-lactamase enzyme. J Antimicrob Chemother 2014;69:2942-6.

119.Lahiri SD, Johnstone MR, Ross PL, et al. Avibactam and class $\mathrm{C}$ beta-lactamases: mechanism of inhibition, conservation of the binding pocket, and implications for resistance. Antimicrob Agents Chemother 2014;58:5704-13.

120. Papp-Wallace KM, Winkler ML, Taracila MA, et al. Variants of beta-lactamase KPC-2 that are resistant to inhibition by avibactam. Antimicrob Agents Chemother 2015;59:3710-7.

121. Castanheira M, Mills JC, Costello SE, et al. Ceftazidimeavibactam activity tested against Enterobacteriaceae isolates from U.S. hospitals (2011 to 2013) and characterization of $\beta$-lactamase-producing strains. Antimicrob Agents Chemother 2015;59:3509-3517.

122. Castanheira M, Mendes RE, Sader HS. Low Frequency of Ceftazidime-Avibactam Resistance among Enterobacteriaceae Isolates Carrying blaKPC Collected in U.S. Hospitals from 2012 to 2015. Antimicrob Agents Chemother 2017;61:e02369-16.

123. Humphries RM, Yang S, Hemarajata P, et al. First report of ceftazidime-avibactam resistance in a KPC-3-expressing Klebsiella pneumoniae isolate. Antimicrob Agents Chemother 2015;59:6605-7.

124. Krishnan NP, Nguyen NQ, Papp-Wallace KM, et al. Inhibition of Klebsiella beta-Lactamases (SHV-1 and KPC-2) by avibactam: a structural study. PLoS One 2015;10:e0136813.

125.Livermore DM, Warner M, Jamrozy D, et al. In vitro selection of ceftazidimeavibactam resistance in Enterobacteriaceae with KPC-3 carbapenemase. Antimicrob Agents Chemother 2015;59:5324-30.

126. Shields RK, Nguyen MH, Press EG, et al. In Vitro Selection of Meropenem Resistance among CeftazidimeAvibactam-Resistant, Meropenem-Susceptible Klebsiella pneumoniae Isolates with Variant KPC-3 Carbapenemases. Antimicrob Agents Chemother 2017;61:e00079-17.

127.Lahiri SD, Mangani S, Jahic H, et al. Molecular basis of selective inhibition and slow reversibility of avibactam against class D carbapenemases: a structureguided study of OXA-24 and OXA-48. ACS Chem Biol 2015;10:591-600.

128. Yoshizumi A, Ishii Y, Aoki K, et al. In vitro susceptibility of characterized beta-lactamase-producing Gram-negative bacteria isolated in Japan to ceftazidime-, ceftaroline-, and aztreonam-avibactam combinations. J Infect Chemother 2015;21:148-51.

129. Winkler ML, Papp-Wallace KM, Taracila MA, et al. Avibactam and inhibitor-resistant SHV beta-lactamases. Antimicrob Agents Chemother 2015;59:3700-9.

130. Sader HS, Castanheira M, Mendes RE, et al. Ceftazidimeavibactam activity against multidrug-resistant Pseudomonas aeruginosa isolated in US medical centers in 2012 and 2013. Antimicrob Agents Chemother 2015;59:3656-9.

131.Alatoom A, Elsayed H, Lawlor K, et al. Comparison of antimicrobial activity between ceftolozanetazobactam and ceftazidime-avibactam against multidrugresistant isolates of Escherichia coli, Klebsiella pneumoniae, and Pseudomonas aeruginosa. Int J Infect Dis 2017;62:39-43. 132. Torres A, Rank D, Melnick D, et al. Randomized Trial 
of Ceftazidime-Avibactam vs Meropenem for Treatment of Hospital-Acquired and Ventilator-Associated Bacterial Pneumonia (REPROVE): Analyses per US FDA-Specified End Points. Open Forum Infect Dis 2019;6:ofz149.

133. Mehta M, Uhlemann AC. Beware of broad-spectrum generalizations: ceftazidime-avibactam compared to meropenem for the treatment of gram-negative pneumonia. J Emerg Crit Care Med 2018;2:45.

134. Kalil AC, Klompas M. Ceftazidime-avibactam versus meropenem for the treatment of nosocomial pneumonia. Lancet Infect Dis 2018;18:229-31.

135. Nicolau DP, Siew L, Armstrong J, et al. Phase 1 study assessing the steady-state concentration of ceftazidime and avibactam in plasma and epithelial lining fluid following two dosing regimens. J Antimicrob Chemother 2015;70:2862-9.

136. Almarzoky Abuhussain SS, Kuti JL, Nicolau DP. Antibacterial Activity of Human Simulated Epithelial Lining Fluid Concentrations of Ceftazidime-Avibactam Alone or in Combination with Amikacin Inhale (BAY416551) against Carbapenem-Resistant Pseudomonas aeruginosa and Klebsiella pneumoniae. Antimicrob Agents Chemother 2018;62:e00113-18.

137. Dimelow R, Wright JG, MacPherson M, et al. Population Pharmacokinetic Modelling of Ceftazidime and Avibactam in the Plasma and Epithelial Lining Fluid of Healthy Volunteers. Drugs R D 2018;18:221-30.

138. Housman ST, Crandon JL, Nichols WW, et al. Efficacies of ceftazidime-avibactam and ceftazidime against Pseudomonas aeruginosa in a murine lung infection model. Antimicrob Agents Chemother 2014;58:1365-71.

139. Falcone M, Viale P, Tiseo G, et al. Pharmacokinetic drug evaluation of avibactam + ceftazidime for the treatment of hospital-acquired pneumonia. Expert Opin Drug Metab Toxicol 2018;14:331-40.

140. Shields RK, Nguyen MH, Chen L, et al. Pneumonia and Renal Replacement Therapy Are Risk Factors for Ceftazidime-Avibactam Treatment Failures and Resistance among Patients with Carbapenem-Resistant Enterobacteriaceae Infections. Antimicrob Agents Chemother 2018;62:e02497-17.

141. Wang Y, Wang J, Wang R, et al. Resistance to Ceftazidime-Avibactam and Underlying Mechanisms. J Glob Antimicrob Resist 2019;22:18-27.

142. Sheu CC, Chang YT, Lin SY, et al. Infections Caused by Carbapenem-Resistant Enterobacteriaceae: An Update on Therapeutic Options. Front Microbiol 2019;10:80.

143. Mirza HC, Hortaç E, Koçak AA, et al. In vitro activity of ceftolozane-tazobactam and ceftazidime-avibactam against clinical isolates of meropenem-non-susceptible Pseudomonas aeruginosa: A two-centre study. J Glob Antimicrob Resist 2020;20:334-8.

144.Ho S, Nguyen L, Trinh T, et al. Recognizing and Overcoming Resistance to New Beta-Lactam/BetaLactamase Inhibitor Combinations. Curr Infect Dis Rep 2019;21:39.

145.Karaiskos I, Lagou S, Pontikis K, et al. The "Old" and the "New" Antibiotics for MDR Gram-Negative Pathogens: For Whom, When, and How. Front Public Health 2019;7:151.

146. Scott LJ. Ceftaroline fosamil: a review in complicated skin and soft tissue infections and community-acquired pneumonia. Drugs 2016;76:1659-74.

147. Cosimi RA, Beik N, Kubiak DW, et al. Ceftaroline for Severe Methicillin-Resistant Staphylococcus aureus Infections: A Systematic Review. Open Forum Infect Dis 2017;4:ofx084.

148.Poon H, Chang MH, Fung HB. Ceftaroline fosamil: a cephalosporin with activity against methicillin-resistant Staphylococcus aureus. Clin Ther 2012;34:743-65.

149. Steed ME, Rybak MJ. Ceftaroline: a new cephalosporin with activity against resistant gram-positive pathogens. Pharmacotherapy 2010;30:375-89.

150.Zhanel GG, Sniezek G, Schweizer F, et al. Ceftaroline: a novel broad-spectrum cephalosporin with activity against meticillin-resistant Staphylococcus aureus. Drugs 2009;69:809-31.

151.Jorgenson MR, DePestel DD, Carver PL. Ceftaroline fosamil: a novel broad-spectrum cephalosporin with activity against methicillin-resistant Staphylococcus aureus. Ann Pharmacother 2011;45:1384-98.

152.Lodise TP, Low DE. Ceftaroline fosamil in the treatment of community-acquired bacterial pneumonia and acute bacterial skin and skin structure infections. Drugs 2012;72:1473-93.

153.Lan SH, Chang SP, Lai CC, et al. Ceftaroline Efficacy and Safety in Treatment of Complicated Skin and Soft Tissue Infection: A Systemic Review and Meta-Analysis of Randomized Controlled Trials. J Clin Med 2019;8:776.

154. Bae IG, Stone GG. Activity of ceftaroline against pathogens associated with community-acquired pneumonia collected as part of the AWARE surveillance program, 2015-2016. Diagn Microbiol Infect Dis 2019;95:114843.

155.Lodise TP, Anzueto AR, Weber DJ, et al. Assessment of time to clinical response, a proxy for discharge readiness, among hospitalized patients with community-acquired 
pneumonia who received either ceftaroline fosamil or ceftriaxone in two phase III FOCUS trials. Antimicrob Agents Chemother 2015;59:1119-26.

156. Riccobene TA, Pushkin R, Jandourek A, et al. Penetration of Ceftaroline into the Epithelial Lining Fluid of Healthy Adult Subjects. Antimicrob Agents Chemother 2016;60:5849-57.

157. MacVane SH, So W, Nicolau DP, et al. In vitro activity of human-simulated epithelial lining fluid exposures of ceftaroline, ceftriaxone, and vancomycin against methicillin-susceptible and -resistant Staphylococcus aureus. Antimicrob Agents Chemother 2014;58:7520-6.

158. Bhalodi AA, Crandon JL, Biek D, et al. Efficacy of ceftaroline fosamil in a staphylococcal murine pneumonia model. Antimicrob Agents Chemother 2012;56:6160-5.

159.Lan SH, Chang SP, Lai CC, et al. Efficacy and Safety of

Cite this article as: Lupia T, Corcione S, Mornese Pinna S, De Rosa FG. New cephalosporins for the treatment of pneumonia in internal medicine wards. J Thorac Dis 2020;12(7):3747-3763. doi: $10.21037 /$ jtd-20-417
Ceftaroline for the Treatment of Community-Acquired Pneumonia: A Systemic Review and Meta-Analysis of Randomized Controlled Trials. J Clin Med 2019;8:824. 160.Eljaaly K, Wali H, Basilim A, et al. Clinical cure with ceftriaxone versus ceftaroline or ceftobiprole in the treatment of staphylococcal pneumonia: a systematic review and meta-analysis. Int J Antimicrob Agents 2019;54:149-53.

161. Cristinacce A, Wright JG, Stone GG, et al. A Retrospective Analysis of Probability of Target Attainment in Community-Acquired Pneumonia: Ceftaroline Fosamil Versus Comparators. Infect Dis Ther 2019;8:185-98.

162. Rosanova MT, Aguilar PS, Sberna N, et al. Efficacy and safety of ceftaroline: systematic review and meta-analysis. Ther Adv Infect Dis 2018 Nov 2;6:2049936118808655. 